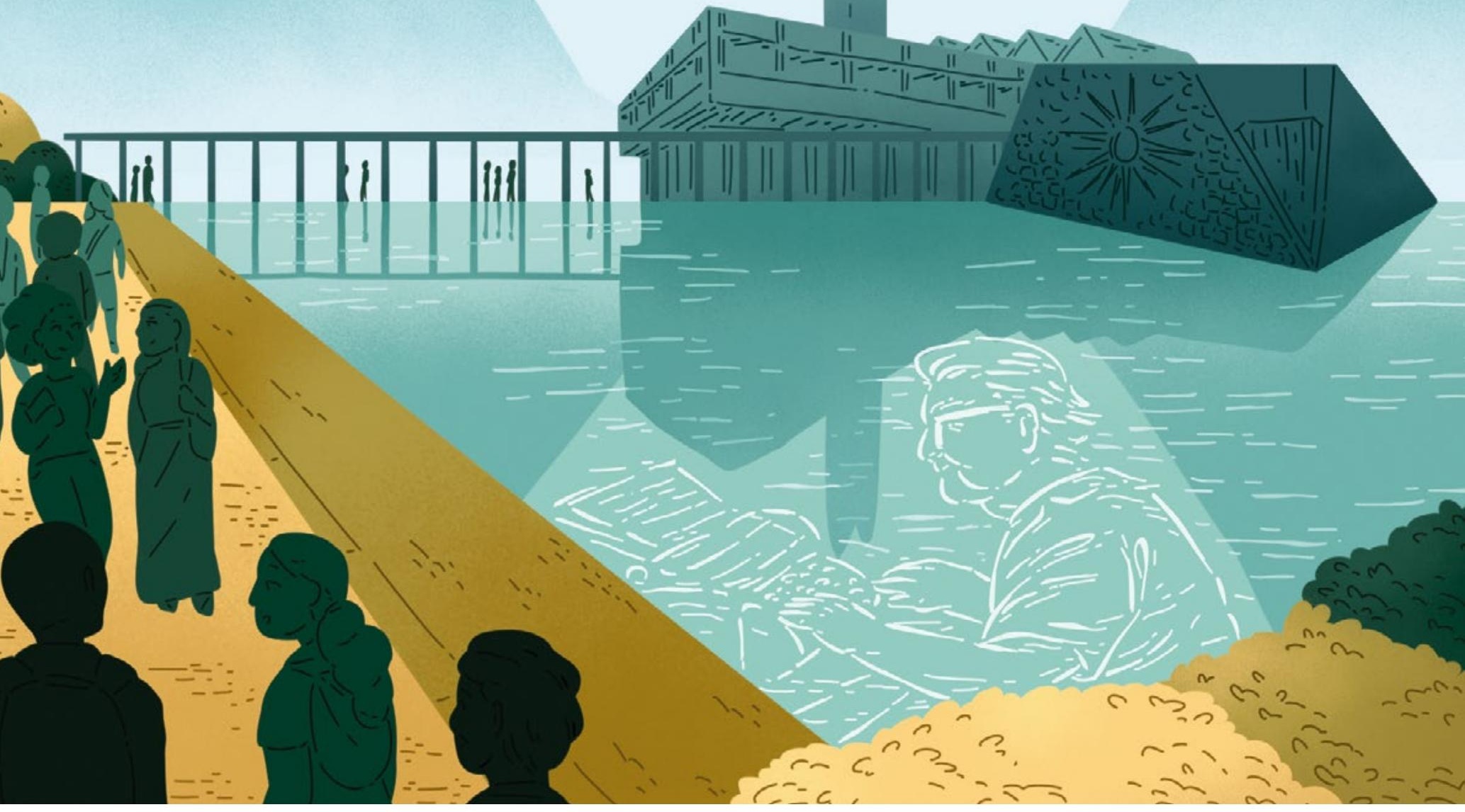

\title{
A HORA IMORTAL DA UNIVERSIDADE
}

Humberto Hermenegildo de Araújo ${ }^{1}$

Apresentado por Luís da Câmara Cascudo (1898-1986) como aula inaugural da Universidade Federal do Rio Grande do Norte - UFRN, em 21 de março de 1959, o discurso Universidade e Civilização reveste-se de alto valor documental, inclusive pela sua atualidade. O orador da solenidade de instalação da universidade abre o seu texto com uma afirmativa que remete à imortalidade da instituição recém-criada: "Durante um minuto o relógio do tempo marca para o Rio Grande do Norte a sua hora imortal". Se vincularmos esta afirmativa ao sentido de "permanência", teremos uma chave de leitura que parte do título do texto: "Universidade e Civilização".
Nesse título, os dois vocábulos que o formam estão ligados por uma relação coordenativa e de espelhamento, significando que um não existe sem o outro, no contexto em que são enfocados. Assim, imortalidade compreende a permanente construção da universidade como empenho civilizatório e, ao mesmo tempo, o permanente aperfeiçoamento da civilização com a mediação da universidade. Acresce que o contexto referido contempla o "alvoroço provinciano", porque a universidade é "do Rio Grande do Norte". Com tal liame, ela deve estender a esse lugar as atividades resultantes dos conhecimentos gerados institucionalmente. 
Com esse raciocínio, o autor do discurso passa a estender uma rede de imagens que simbolizam alicerces da imortalidade pretendida. Os vocábulos "criança", "semente", "potencialidade", "sonho", "colheita", "seara", "berço", "esperança" e "batismo" formam, nos nove primeiros parágrafos do texto, um campo semântico positivo que desagua nas noções de Universal e Humano, Civilização e Gultura². O encadeamento das conotações criadas pelo uso desses vocábulos tem por referencial uma série de fatos: o sonho informe e longo dos velhos professores do passado ${ }^{3}$, a memória das grandes universidades históricas ${ }^{4}$, a humilde história local. Nesse último capítulo, ressalta o orador: "Nesta noite, [...] estarão presentes todos quantos pressentiram a existência desta instalação". Pressentir significa, diante dos escritos cascudianos que se colocam à margem do discurso inaugural da nossa universidade, algo diverso dos sentidos de adivinhar ou pressagiar: estamos mais próximos, semanticamente, dos sentidos de conjeturar e calcular um fato iminente.

Neste sentido, o pressentimento de que a universidade viria para o Rio Grande do Norte já havia sido alvo de especulações, pelo autor do discurso, há trinta anos: em artigo publicado no jornal $A$ República, sob o título "E a nossa Universidade Popular?" (24 jan. 1929)5 , Câmara Cascudo relata que, no ano anterior, o Instituto Histórico anunciara uma série de conferências sob a denominação de "Universidade Popular" e que, no entanto, não se concretizaram. Na matéria, ele propõe a retomada da atividade como um evento mensal, uma palestra sobre alguma coisa "[...] de que não sabemos ou sabemos pouco". Nas sugestões das palestras, percebe-se a simpatia pelos temas regionais e da cultura popular, a exemplo do interesse pelos remédios populares e pela vida nas velhas fazendas sertanejas, de modo a superar a triste fisionomia da cidade "[...] que está virando cemitério de aldeia à meia noite".

Após vinte anos daquela primeira tentativa, o tema da universidade popular ressurge no texto "Universidade popular do Rio Grande do Norte" (A República, 29 mar. 1949) gramação dessa instituição que fora instalada em $1^{\circ}$ de maio de 1948, no Instituto Histórico e Geográfico do Rio Grande do Norte. A iniciativa de Câmara Cascudo, no final dos anos 40, está inserida em um movimento que Itamar de Souza (1984) considera como primórdios da vida universitária local, compreendendo as fases "Lírica" e "Heroica".

A fase lírica, correspondente ao surgimento das chamadas universidades populares, é caracterizada por iniciativas das elites intelectuais e políticas dominantes, em contraposição a movimentos populares e de classe. Não por acaso, a primeira universidade popular foi criada no dia $1^{\circ}$ de maio de 1925, pelo Governador José Augusto Bezerra de Medeiros, com o apoio da igreja católica.

O movimento liderado por Câmara Cascudo surgiu depois da criação das faculdades de Farmácia e Odontologia, além da Escola de Serviço Social, ou seja, ainda na fase heroica, quando surgiram as faculdades, entre as décadas de 40 e 50 do século passado. Ainda

\footnotetext{
${ }^{2}$ Conceitos que seriam desenvolvidos no livro Civilização e Cultura: pesquisas e notas de etnografia geral, publicado em 1973. De acordo com a nota preliminar do autor-professor, escrita em 1962, a produção do texto se deu ao longo de seis anos: “Trabalho em dezembro, quando os cursos estão encerrados e eu posso viajar na quarta dimensão das simpatias bibliográficas, além das limitações dos currículos" (CASCUDO, 1983, p. 15). Nove anos depois, uma nova nota relata a história dos originais que se perderam e reapareceram para, enfim, serem publicados pela editora José Olympio graças ao empenho da UFRN: 0 então reitor, Onofre Lopes, quis prestar com a publicação uma homenagem “[...] não a mim [...], mas aos professores provincianos do Brasil Universitário" (Ibid., p. 24).

${ }^{3}$ Ao longo dos seus esparsos publicados na imprensa natalense, Câmara Cascudo homenageou esses mestres, a exemplo do clérigo Mateus Duarte (" 0 mestre da gramática latina". A República, 17 jul. 1940); de Joaquim Apolinar Pereira de Brito ("0 primeiro mestre de latim no Caicó". A República, 3 set. 1940); do Padre Antônio Xavier Garcia de Almeida ("0 primeiro diretor do Ateneu". A República, 18 abr. 1941); de Maria Montezuma, professora em Canguaretama-RN ("Voz de outrora". A República, 17 fev. 1946); de Pedro Alexandrino ("Lembrando Pedro Alexandrino". Diário de Natal, 13 jul. 1949); de Francisco Ivo Cavalcanti ("Francisco Ivo Cavalcanti". Centro de Imprensa, Natal, abr., 1947).

${ }^{4}$ Também em um dos seus esparsos publicados na imprensa local, destaca-se o reconhecimento da importância histórica da Universidade de Coimbra para a formação do Brasil ("A voz de Coimbra". A República, 7 out. 1943).

${ }^{5}$ Publicado em Crônicas de origem: a cidade do Natal nas crônicas cascudianas dos anos 20 (CASCUDO, 2005).

${ }^{6}$ Documento do acervo do Ludovicus - Instituto Câmara Cascudo.
} 
segundo Itamar de Souza, a ideia da iniciativa vinha da Europa, particularmente, da Espanha de Franco. A estrutura e a função dessa universidade é assim resumida:

As aulas, em número de dezoito ${ }^{7}$, foram quase todas ministradas no Instituto Histórico e Geográfico, às quartas-feiras, no horário das 20 horas. A assistência se avolumava de aula para aula. (SOUZA, 1984, p. 27)

Para que serviu esta Universidade Popular? No contexto de 1948, ela representou um movimento intelectual capaz de suscitar nas elites natalenses a consciência do seu valor. E, inegavelmente, fermentou a ideia de Universidade que seria concretizada no final da década de 50. (SOUZA,1984, p. 29)

Como se percebe, "a humilde história local"8 significa, de fato, um empenho civilizatório que o orador restaura, no seu discurso, para fazer jus ao qualificativo "Rio Grande do Norte" da universidade. Por isso, o seguinte esclarecimento:

Se a Universidade dará os cursos regimentais aos seus estudantes, matriculados nas Faculdades, ministrando ensinamentos para a batalha profissional, cumprirá apenas a materialidade de sua missão, realizando tão-somente a tarefa maquinal de uma transmissão de técnicas. (CASCUDO, 1988, p. 13)

A advertência contra a instrumentalização como um fim exclusivo de transmissão de técnicas está, no texto cascudiano, a serviço de um sujeito que perora em favor do conceito de civilização, que é o eixo central do argumento do orador na sua defesa da universidade. Nesse conceito, as categorias de universal e de humano permitiriam aos professores a superação da tarefa maquinal de uma transmissão de técnicas, como exemplifica o ciumento orador: para ele, os professores devem ser "[...] veteranos da campanha de sonhar e sofrer, dando aos seus alunos não unicamente a lição dos livros mas a impressão pessoal na viagem pelo mundo e pela sensibilidade" (CASCUDO, 1988, p. 14. Grifo meu). Trata-se, portanto, da "valorização humana da ciência adquirida". Assim, a finalidade educacional da universidade seria congregar saberes, culturas, em proveito de uma civilização. Nessa conjugação, a função dos saberes nunca se esgotaria na aplicabilidade imediata:

Precisamos de quem atenda aos enfermos, erga edifícios, estradas, pontes e túneis, manipule (agora com o luxo diluvial dos remédios feitos, "oficinais", quase ninguém reclama os velhos "magistrais" de outrora, julgados infalíveis e sem consequências maiores), manipulando nos laboratórios e farmácias, dê assistência ao Social, conheça Odontologia, as Línguas Neolatinas, Geografia, História, em cursos especializados, e ainda a ciência da Economia e Finanças, Belas-Artes, Música, mas "tudo isso e o Céu também" pedimos, numa exigência acima das formas positivas das Culturas indispensáveis nesta segunda metade do século XX. No ano de 2059 as solicitações serão diversas, mas as "clássicas" continuarão inalteráveis como rochedos n'água corrente. (CASCUDO, 1988, p. 18-19)

Após os parágrafos citados, o orador define a universidade como uma "uma escola perene de pesquisas" e, mais adiante, chega ao ponto em que especifica a civilização que defende:

A universidade deve valorizar, estudar, defender a Civilização do Brasil. Primeiro porque é bela, sugestiva, original, humana. Segundo porque é nossa. Conhecê-la, amá-la, compreendê-la pela pesquisa que fatalmente terá de fazer em sua vida profissional, no contato dos problemas a resolver desde o cálculo de resistência de materiais até a redução de uma pulpite rebelde. (CASCUDO, 1988, p. 20)

Como estender, contudo, uma ponte entre a civilização brasileira e aquelas categorias de universal e humano? Neste ponto, o orador recorre à noção de solidariedade numa concepção

\footnotetext{
${ }^{7}$ No seu texto, Cascudo (1949) apresenta a programação em 21 aulas (quatro em maio, três em junho, quatro em julho, quatro em agosto, quatro em setembro e duas em outubro). Desse total, um quarto (cinco aulas) foi dedicado a um curso sobre a História da Literatura Norte-rio-grandense, tendo como ministrante o próprio Câmara Cascudo.

${ }^{8}$ Ao analisar o discurso cascudiano, Marcos Silva (2004) declara: "Esse evento foi caracterizado pelo Orador como capaz de transcender um momento imediato, recuperando, simultaneamente, a historicidade de Educação e Cultura no Rio Grande do Norte, desde o século XVIII, e lançando bases para um futuro que valorizasse mais Civilização e Cultura.
} 
bastante próxima do conceito de fraternidade ${ }^{9}$, ou seja, não exatamente no sentido político que a modernidade deu àquela noção:

Ter o sentimento da solidariedade humana, a compreensão imediata de fatores universais que atuam perto de nós e em nós mesmos. Sentir-se parte no mundo, não entre os Homens mas com os Homens. Que o solidarismo humano não é determinismo político, mas dogma divino de fraternidade. Conservar o zelo em admirar as tarefas estranhas à sua profissão. Julgar úteis todos os que trabalham

(CASCUDO, 1988, p. 20)

Câmara Cascudo promove, com essa noção de solidariedade humana, um desrecalque de valores construídos historicamente pela cultura colonial $^{10}$, numa elevação da autoestima nacional com a mediação da universidade:

Valorizar o Brasil para que possamos ser dignos colaboradores no esforço cultural do Mundo, levando ajuda de nossa competência. Prepararmo-nos excelentemente para resistir às rivalidades e às concorrências. Lembrar que, espiritual, étnica e biologicamente, não temos elementos negativos que impossibilitem ou limitem a nossa percepção e aquisição científica.

Somos iguais aos outros. Nem mais e nem menos. Nas virtudes e nos defeitos, nas proporções relativas ao tempo de existência e densidade demográfica.

$[\ldots]$

Assim a missão universitária, sua alma, é preparar os valorizadores da Civilização Brasileira, ampliadores das Culturas, em serviço da Humanidade.

(CASCUDO, 1988, p. 20-21)
A apreciação do orador sobre a civilização brasileira é mantida em um texto da famosa série Acta diurna, sob o título "Ora! A Universidade..."11, publicado no dia 29 de abril de 1959, no jornal $A$ República - portanto, uma semana após a leitura do discurso de instalação da universidade em sessão pública. Seria o mesmo discurso em uma versão reduzida? Tratar-se-ia da paráfrase de alguns trechos? Qual é a especificidade dessa Acta diurna?

Antes, porém, de opinar sobre o pequeno texto publicado no jornal natalense, faz-se necessário expressar um estranhamento de leitor com relação ao discurso publicado pela Universidade Federal do Rio Grande do Norte: está ausente, no texto oficial, a saudação às autoridades presentes no auditório. Terá o autor rompido com a tradição do gênero, em plena solenidade, ou terá sido omitido na versão impressa esse elemento inicial do discurso? O estranhamento se dá não apenas pela ausência da saudação, mas, especialmente, pela referência de forma generalizada, no texto da Acta diurna, aos representantes das elites políticas e econômicas locais. Seria, tal referência, um índice do porquê da ausência da saudação no discurso oficial? De qualquer modo, não importa tanto a ausência da saudação e sim o teor da referência às elites, por se tratar de um indicador do grau de simpatia do orador pela questão da fraternidade cristã que se vincula ao

\footnotetext{
${ }^{9}$ Sobre 0 tema, cf. os estudos organizados por Antonio Maria Baggio $(2008 ; 2009)$ nos dois volumes de O princípio esquecido. Trata-se da categoria temática da fraternidade não-burguesa, que promove uma releitura do que foi historicamente idealizado pela burguesia como categoria política e, por inversão histórica, reduzido, na prática, a um gesto de filantropia exercido por pessoas pobres e desvalidas, como uma ação sem ambição política e próxima dos exemplos bíblicos de filantropia. Nessa perspectiva, a fraternidade é demonstrada como o princípio esquecido da Revolução Francesa e daria uma dimensão do fracasso dos projetos humanísticos burgueses desde o limiar da era moderna, como uma contradição histórica. Os autores proporcionam uma visão de dois aspectos da fraternidade: a origem judaico-cristã e um conjunto de conceituações sobre 0 sentido adquirido pela fraternidade depois do lluminismo e da Revolução Francesa. Evidentemente, os estudos não apostam na disponibilidade voluntária das pessoas para fins de transformação, aspecto que é altamente dificultado no estágio histórico em que 0 individualismo atinge escalas sem precedentes.

${ }^{10}$ Assim como a concepção de solidariedade adotada permite um diálogo com a categoria temática da fraternidade não-burguesa, o posicionamento sobre a civilização brasileira está próximo das teses modernistas, movimento acompanhado de perto por Câmara Cascudo, sobretudo ao longo dos anos 1920. Antonio Candido identifica o modo como se deu, no processo modernista brasileiro, a aceitação ou mesmo redenção das componentes recalcadas da nacionalidade, com ênfase para o desrecalque localista: "[...]a cada valor aceito na tradição acadêmica e oficial correspondia, na tradição popular, um valor recalcado que precisava adquirir estado de literatura" (CANDIDO, 1980, p. 120). Nesse contexto, dentre os elementos recalcados da nossa civilização destacam-se 0 negro, 0 mestiço, o filho de imigrantes, 0 gosto vistoso do povo, a ingenuidade, a malandrice. 0 estudioso chama a atenção para a importância da obra de Gilberto Freyre, representativa do ensaio histórico-sociológico, que assinala a expressão, neste terreno, das mesmas tendências do modernismo na ficção. Por fim, afirma que os ensaios desse gênero se multiplicam nos anos de 1930, um "[...] decênio de intensa pesquisa e interpretação do país. Ajustando-se a uma tendência secular, o pensamento brasileiro se exprime, ainda aí, no terreno predileto e sincrético do ensaio não especializado de assunto histórico-social" (Ibid., p. 124). Identificaríamos nesse movimento, portanto, a raiz do apreço cascudiano pela civilização brasileira, na perspectiva vislumbrada por Antonio Candido: "Parece que o Modernismo (tomado 0 conceito no sentido amplo de movimento das ideias, e não apenas das letras) corresponde à tendência mais autêntica da arte e do pensamento brasileiro. Nele, e sobretudo na culminância em que todos os seus frutos amadureceram (1930-1940), fundiram-se a libertação do academismo, dos recalques históricos, do oficialismo literário; as tendências de educação política e reforma social; 0 ardor de conhecer o país" (Ibid., p. 124).

${ }^{11} 0$ texto foi também publicado no volume IX de 0 livro das velhas figuras (CASCUDO, 2005). Zila Mamede (1970, p. 515) registra o mesmo documento com outro título: "Ora a nossa Universidade".
} 
sentido de solidariedade humana no contexto do discurso analisado. A sua referência, direta, soa quase como uma denúncia do histórico desinteresse das elites com relação ao ensino superior, pelo menos até aquele momento:

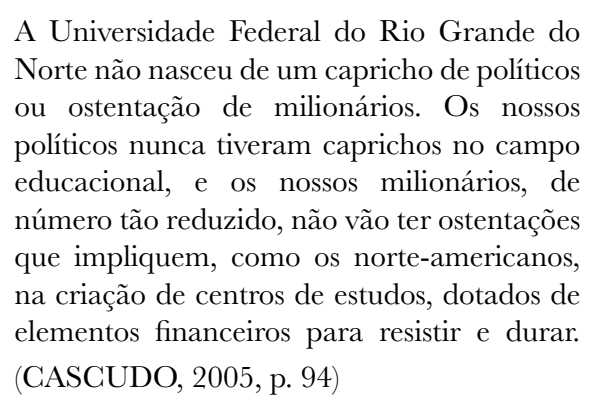

Em contraposição à pobreza de espírito daquelas elites, é ressaltado o sonho de professores e estudantes:

\begin{abstract}
A universidade nasceu justamente na hora de nascer porque era sonho de lento e ininterrupto crescimento. Nunca deixou de estar no pensamento dos professores norte-rio-grandenses o desejo da fixação dos nossos estudantes nas faculdades locais. Era com experiência própria e reminiscência pessoal que os estudantes pobres, constituindo a totalidade, recordavam os sacrifícios dos cursos fora da terra natal e a significação dolorosa das provações vencidas para a conquista do diploma final.(CASCUDO, 2005, p. 94)
\end{abstract}

Os parágrafos seguintes do texto seguem no mesmo tom do discurso Universidade e Civilização, mas o seu final surpreende novamente, pois o leitor está diante de uma possível resposta a alguma provocação que teria irritado o orador:

Uma universidade jamais merece críticos espontâneos, adversários por vocação negativista, recenseadores de falhas, topógrafos de enganos, estatísticos de omissões.

Deve ter amigos que a orientem, amparem e prestigiem...

(CASCUDO, 2005, p. 94)

A apresentação dos textos cascudianos dispostos à margem do discurso inaugural da nossa universidade tem o objetivo de sugerir que havia uma tensão no processo de construção institucional, certamente causada pela luta de classes. O lugar social do orador é o mesmo daqueles que possuem a pobreza de espírito, mas a sua voz tem conotação fraterna. Graças ao tom dessa voz solidária, ideal, ele consegue erguer, contrariando o seu posicionamento social, uma representação que promete superar algo que está nas entrelinhas do texto como um alerta sobre a função comunitária da instituição de ensino superior. A tensão referida reside no questionamento sobre os sujeitos da universidade, que é o tema da parte final de Universidade e Civilização.

Assim, o processo de construção institucional opõe, de um lado, as elites locais - que, certamente, querem para os seus herdeiros a universidade - e, do outro lado, aqueles que não puderam ter uma representação em tal processo. No entanto, como não depende exclusivamente de um dos lados opostos a partilha da construção e dos seus benefícios, a voz daqueles que foram secularmente silenciados emerge, de algum modo, no discurso do orador, graças a uma simpatia ou a uma contradição de classe. Os trabalhadores entram nesse discurso porque sem eles o título Universidade e Civilização não se sustentaria com o sentido de "permanência" aludido no início deste artigo. Eis a sua chegada triunfal, embora melancólica, haja vista a história da dominação no Brasil:

Lembremo-nos também que os nacionais de todos os países têm denominações étnicas. Nós somos os únicos significando uma profissão. Brasileiro, no século do Descobrimento, era o homem que trabalhava o Pau-brasil. Cortava, arrumava, transportava ibirabitanga para a exportação. Iam as naus, gemente nos alísios o velame bojudo, carregadas de pau-brasil, esforço dos brasileiros.

$[\ldots]$

A missão da Universidade é prestigiar a velha vocação brasileira do Trabalho. Brasil, Terra de Trabalho, afastando o sedutor namoro da ilha dos Papagaios, palrantes, atraentes, imitadores eternos de todos os idiomas, de todos os ruídos, de todas as sonoridades, sem que mais possuam canto e ritmo próprios, perdidos, dispersados pelo uso diário e secular do plágio. Melhor é um pássaro com a monotonia do canto próprio e seu do que esta soberba ave vitoriosa na polifonia fraudulenta de suas contrafações repetidas. (CASCUDO, 1988, p. 22) 
Com palavras que evocam trabalho, o orador destaca a opção por um território, não obstante a percepção da globalidade do mundo. Assinala, igualmente, a percepção sobre os cosmopolitas papagaios, possuidores de vozes e cores que podem representar, alegoricamente, a sedução das modas em contraponto ao aparente monótono trabalho situado, como uma permanente, no movimento dialético do localismo e do cosmopolitismo, caracterizador da nossa formação ${ }^{12}$.

Se atualizarmos o discurso para o século XXI, teremos aí uma perspectiva inclusiva: a universidade deve ser também dos trabalhadores e não uma exclusividade das elites oligárquicas. Tal perspectiva inclusiva não pode significar, contudo, que a conquista da universidade, pelos excluídos, seja um fruto da fraternidade, uma vez que esse princípio foi há muito bloqueado pelos colonizadores e se tornou socialmente ineficaz. Como protagonistas da história, os professores abnegados são convocados porque carregam, provavelmente, valores desprezados pela sociedade. Por meio da memória, portanto, a fraternidade se impõe simbolicamente no discurso.
Se atualizarmos, contudo, a recepção do documento histórico analisado, veremos que as contradições apontadas subsistem, mas a universidade ainda é vista como uma cidade ideal das elites dominantes. Para desvelar essa imagem, no presente, como um meio de provocar a explicitação das desigualdades, devemos refletir sobre a adoção de medidas inclusivas voltadas para a educação, a exemplo da adoção do sistema de cotas nas universidades como uma política de ação afirmativa, motivo de grande polêmica nacional nos últimos anos.

Tendo em mente a imposição simbólica do desejo dos professores norte-rio-grandenses e dos estudantes pobres no discurso cascudiano, questionamos, por fim: não residiria na adoção da política afirmativa referida o ensejo de religar o saber da universidade com a sabedoria popular de quem foi silenciado na sua construção? Recordemos o lema "O melhor do Brasil é o brasileiro" ${ }^{13}$, adotado há poucos anos pelo governo federal como slogan em campanhas institucionais. A esse brasileiro cabe o direito de conhecer a sua realidade e esse é um direito de penosa conquista ${ }^{14}$, no âmbito do que o orador da solenidade de instalação da nossa universidade considerou como empenho civilizatório.

\footnotetext{
${ }^{12}$ Ao analisar a formação do sistema literário brasileiro, Antonio Candido (1980, p. 110) identifica a chamada "dialética do localismo e do cosmopolitismo" que, segundo ele, é realizado "[...] por meio da tensão entre o dado local (que se apresenta como substância da expressão) e os moldes herdados da tradição europeia (que se apresentam como forma da expressão)". Reconhecendo a especificidade da análise, que é do campo dos estudos literários, sugerimos ampliar a percepção desse movimento para chegar à compreensão do modo como Câmara Cascudo se insere no moderno pensamento nacional.

${ }^{13}$ "0 melhor produto do Brasil ainda é o brasileiro", segundo Diogenes da Cunha Lima (2016, p. 138).

13“Exemplifiquemos, a propósito, dois casos apontados por Câmara Cascudo de religação entre saberes considerados universais e o conhecimento de uma realidade local: a) a inclusão do curso de História da Literatura Norte-rio-grandense na Universidade Popular de 1949 como antecipação histórica de um fato que demorou mais de cinquenta anos para ser aceito no âmbito da UFRN, no (urso de Letras; b) as relações entre Cultura Popular e Universidade, vistas por Marcos Silva "[...] como diálogo entre Erudições ou lugares da Erudição em suas muitas corporeidades", conforme depoimento: "Tenho lembrança pessoal de ouvir Câmara Cascudo, em palestra natalense de fins dos anos 60, narrando um episódio que deixa patentes aquele diálogo ou esses lugares, relativo à preparação do livro Made in Africa, de 1965. Ele disse que, numa das universidades africanas que visitou, conviveu com eruditos professores locais durante 0 dia. À noite, assistindo a rituais religiosos ligados a tradições tribais, encontrou os mesmos professores como participantes dessas atividades: a erudição acadêmica não os opunha às referidas tradições, dotadas de uma complexidade própria e merecedoras de todo respeito. E Câmara Cascudo lastimou que, no Brasil, tal trânsito cultural não ocorresse com maior frequência"'(SILVA, 2004).
} 


\section{REFERÊNCIAS}

CANDIDO, Antonio. Literatura e cultura de 1900 a 1945. In:

Literatura e sociedade.

6. ed. Rio de Janeiro: Ed. Nacional, 1980. p. 109-138.

CASCUDO, Luís da Câmara. Universidade e civilização. 2. ed. Natal: Editora Universitária, 1988.

CASCUDO, Luís da Câmara. Givilização e cultura: pesquisas e notas de etnografia geral. Belo Horizonte: Itatiaia, 1983.

CASCUDO, Luís da Câmara. E a nossa Universidade Popular? In: Crônicas de origem: a cidade do Natal nas crônicas cascudianas dos anos 20. Natal: EDUFRN/NGGEN/UFRN, 2005. p. 115-118.

CASCUDO, Luís da Câmara. Universidade popular do Rio Grande do Norte. A República, Natal, 29 mar 1949.

CASCUDO, Luís da Câmara. Ora! A Universidade... In: . O livro das velhas figuras: pesquisas e lembranças do Rio Grande do Norte. Vol. IX. Natal: EDUFRN, 2005. p. 94-96.

LIMA, Diogenes da Cunha. Câmara Cascudo: um brasileiro feliz. 4. ed. São Paulo: Escrituras Editora, 2016.

MAMEDE, Zila - Luís da Câmara Cascudo: 50 anos de vida intelectual - 1918/1968; Bibliografia anotada... Natal: Fundação José Augusto, 1970. 2 v. em 3.

SILVA, Marcos Antonio da. História e cultura popular em Câmara Cascudo. Anais do XVII Encontro Regional de História - O lugar da História. ANPUH/SP-UNICAMP. Campinas, 6 a 10 de setembro de 2004. Cd-rom. Acesso em 01/05/2018. Disponível em: http:// www.anpuhsp.org.br/sp/downloads/CD\%20XVII/ST\%20XXII/Marcos\%20Antonio \%20 da $\% 20$ Silva $\% 20-\% 20$ MR.pdf

SOUZA, Itamar de. Universidade: para quê? Para quem? Natal: Clima, 1984.

BAGGIO, Antonio Maria. O princípio esquecido. São Paulo: Editora Cidade Nova, 2008.

BAGGIO, Antonio Maria. O princípio esquecido: exigências, recursos e definições da fraternidade na política. Vargem Grande Paulista-SP: Cidade Nova, 2009. Vol. 2. 


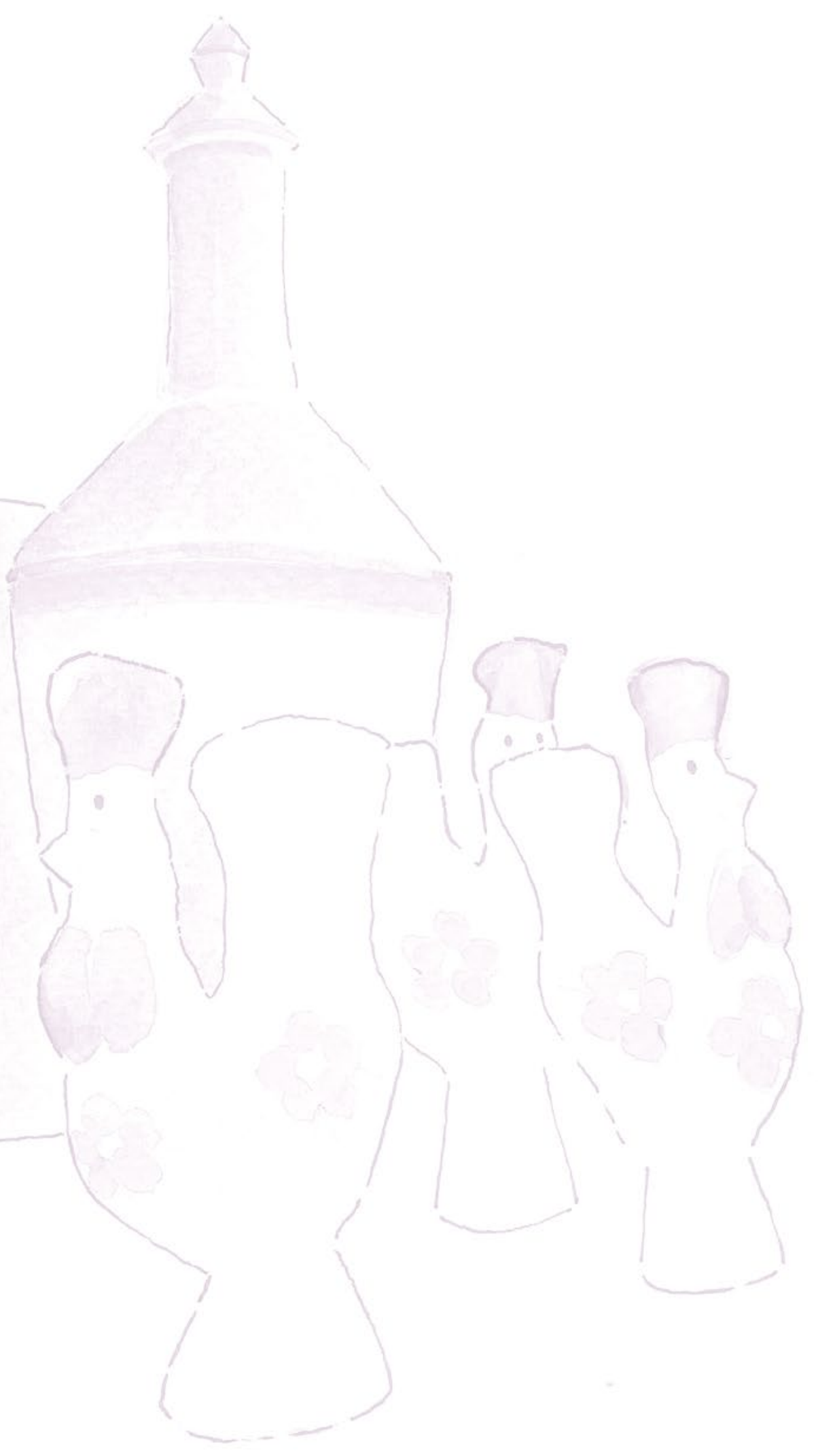

